\title{
Northern Snakes Appear Much More Abundant in Old Fields than in Forests
}

\author{
Francisco Retamal Diaz ${ }^{1,2,3}$ and Gabriel Blouin-Demers ${ }^{1}$ \\ ${ }^{1}$ Department of Biology, University of Ottawa, 30 Marie-Curie, Ottawa, Ontario K1N 6N5 Canada \\ ${ }^{2}$ Current address: Department of Wood and Forest Sciences, Laval University, 2405 Terrasse Street, Québec, Quebec G1V 0A6 \\ Canada \\ ${ }^{3}$ Corresponding author: francisco.retamal-diaz.1@ulaval.ca
}

Retamal Diaz, Francisco and Gabriel Blouin-Demers. 2017. Northern snakes appear much more abundant in old fields than in forests. Canadian Field-Naturalist 131(3): 228-234. https://doi.org/10.22621/cfn.v131i3.1823

Temperature is one of the most important factors regulating habitat selection by ectotherms. Through behavioural thermoregulation, reptiles maintain preferred body temperatures and thereby maximize fitness. At northern latitudes, small colubrids appear to use forest habitat rarely because of thermal constraints. In cool environments, open habitats such as old fields offer more favourable thermal conditions than forest. We studied two northern colubrid snakes, Red-bellied Snake (Storeria occipitomaculata) and Common Gartersnake (Thamnophis sirtalis), in Gatineau Park, Quebec, Canada, to test the hypothesis that small northern snakes are more abundant in open than in closed habitats because open habitats provide better opportunities for thermoregulation. Snakes were sampled using large arrays of tin and plywood coverboards. Snakes were indeed much more abundant in old fields than in forest, and fields offered more favourable thermal conditions. Most snakes were captured in spring and summer (May to August) when temperatures were highest. Storeria occipitomaculata preferred tin over plywood coverboards. We confirmed an apparent strong preference for open habitats in northern snakes.

Key Words: Habitat selection; behavioural thermoregulation; Common Gartersnake; Thamnophis sirtalis; Red-bellied Snake; Storeria occipitomaculata; population density; Gatineau Park

\section{Introduction}

Species face different environmental conditions across their geographic ranges, and these environmental conditions limit their distribution and abundance. The abundant centre hypothesis states that a species' abundance is highest at the centre of its geographic distribution and gradually decreases toward the edges (Brown 1984; Sagarin et al. 2006). At higher latitudes, abiotic factors, such as temperature and sunlight, are believed to limit abundance and distribution of terrestrial species, whereas at lower latitudes biotic factors are believed to be the main limit (Dobzhansky 1950; MacArthur 1972).

The spatial distribution of reptiles is influenced by numerous factors, such as prey density (Madsen and Shine 1996), availability of hibernation sites (Reinert and Kodrich 1982), and proximity to retreat sites (Martino et al. 2011). For the Squamata, temperature is considered to be one of the most important factors regulating habitat selection (Reinert 1993). In ectothermic animals, the necessity to maintain an adequate body temperature is vital for physiological and developmental processes (Peterson et al. 1993). Indeed, body temperature affects physiological, reproductive, and ecological performance (Huey 1982). By adjusting microhabitat selection and timing of activity, ectotherms can thermoregulate effectively (Huey et al. 1989; Krohmer 1989).

In northern latitudes, colubrids appear to use forest rarely, probably because of thermal constraints (Charland and Gregory 1995; Halliday and Blouin-Demers 2016). Black Ratsnakes (Elaphe obsoleta) prefer edges of open habitats because they provide the best opportu- nities for thermoregulation (Blouin-Demers and Weatherhead 2001). Milksnakes (Lampropeltis triangulum) also prefer open habitats with high thermal quality (Row and Blouin-Demers 2006a). Habitats with high thermal quality have a minimal difference between the operative environmental temperature and the preferred body temperature of individuals. Because forest vegetation is dense and does not allow sufficient exposure to sunlight, snakes are expected to use open habitats so that they can bask and achieve preferred body temperatures (Row and Blouin-Demers 2006b).

We tested the hypothesis that small northern snakes are more abundant in open than in closed habitats because open habitats provide better opportunities for thermoregulation. More specifically, we tested the prediction that the number of captures of Common Gartersnakes (Thamnophis sirtalis) and Red-bellied Snakes (Storeria occipitomaculata), both small northern snakes, should be significantly higher in old fields than in forest. We monitored the abundance of small snakes in arrays of coverboards in old fields and in forest in Gatineau Park, Quebec, during their active season in 2015.

Coverboards are effective for sampling snakes (Grant et al. 1992; Houze and Chandler 2002; Ryan et al. 2002), particularly cryptic species (Halliday and BlouinDemers 2015). Coverboards of different sizes (Hecnar and Hecnar 2011) and materials (Engelsoft and Ovaska 2000) can attract different species based on their microhabitat preferences (Hyde and Simons 2001). Coverboards can provide protection from predation as well as thermal benefits (Cooper et al. 1999; Goldsbrough et al. 2006). Coverboards are often made of tin or plywood. 
Tin was more effective than plywood for sampling Common Gartersnakes, Western Terrestrial Gartersnakes (Thamnophis elegans), and Sharp-tailed Snakes (Contia tenuis) in British-Columbia (Engelstoft and Ovaska 2000). Coverboards are preferred over traps because they are economical and safe (Ryan et al. 2002). A secondary objective of our study was to quantify the efficacy of tin and plywood coverboards at attracting small snakes.

\section{Methods}

We sampled snakes at four sites in Gatineau Park $\left(45.50^{\circ} \mathrm{N}, 76.00^{\circ} \mathrm{W}\right)$, Quebec, in summer 2015. All sites were less than $25 \mathrm{~km}$ apart. Although Red-bellied Snake, Common Gartersnake, Smooth Greensnake (Liochlorophis vernalis), Ring-necked Snake (Diadophis punctatus), and Milksnake (Lampropeltis triangulum) were all captured, we only obtained sufficient captures for analysis of Common Gartersnake and Red-bellied Snake. At each of the four sites, we set up two 200-m transects with pairs of coverboards (one roofing tin, one $3 / 4$-inch [2-cm] plywood, both $90 \times 60 \mathrm{~cm}$ ) installed every $10 \mathrm{~m}$, for a total of 320 coverboards. At each site, the transects were parallel to and $50 \mathrm{~m}$ from the edge between old field and forest, one transect in the field and one transect in the forest. The plant community in the old fields consisted mainly of Aster sp., Rhamnus sp., Asclepias sp., Cirsium sp., and Poa spp. All forests were mostly composed of White Birch (Betula papyrifera Marshall), Sugar Maple (Acer saccharum Marshall), and American Beech (Fagus grandifolia Ehrhart). Detailed site descriptions and photographs are available in Appendix S1.

We sampled snakes weekly from 14 May to 16 November 2015. The four sites were visited on the same sunny day between 0800 and 1800 with a weekly rotation in the order in which sites were visited so that they were visited at different times of day. Snakes were hand captured from under the coverboards and each individual was marked by branding one ventral scale with a medical cautery unit (Bovie Aaron Low-Temp Reusable Cautery Unit, Clearwater, Florida, USA; Winne et al. 2006). The date, time, air temperature (at about waist height), temperature under the coverboard, coverboard type (tin or plywood), and habitat type (forest or old field) were recorded for each capture. Individuals were then released immediately at their point of capture. We placed 18 temperature data loggers (iButton thermochron, model DS1921L, Dallas, Sunnyvale, California, USA) under coverboards of both materials and in both habitats at the four sites. The loggers were programmed to measure temperature on the hour between 0800 and 1800 for two periods: from 12 May to 30 July and from 10 September to 23 October.

For both species, we compared the total number of snakes captured (including recaptures) in forest with those captured in field and the total number of snakes captured under tin with those captured under plywood using generalized linear mixed-effects models with a Poisson distribution in R (R Core Team 2012; package lme4; function glmer; family Poisson; Bates et al. 2012). We used a Poisson distribution because the data were zero inflated. Month, habitat, time of capture, ambient temperature, coverboard material, and all interactions were fixed effects, and site identity was a random effect. We compared maximum temperature under tin and plywood coverboards in forest and old field using a linear mixed-effects model in R (package nlme; function lme; Pinheiro et al. 2012). Habitat, cover type, and all interactions were fixed effects and site identity was a random effect.

\section{Results}

We captured 353 snakes (including recaptures) of five species during the 25 weekly visits. Captures remained constant from May until late August and then decreased slowly until November. Common Gartersnakes $(n=90)$ and Red-bellied Snakes $(n=242)$ were the two most abundant species. Rarer species included Smooth Greensnake $(n=2)$, Ring-necked Snake $(n=2)$, and Milksnake $(n=17)$. Total unique captures comprised two Ring-necked Snakes, two Smooth Greensnakes, 13 Milksnakes, 57 Common Gartersnakes, and 171 Red-bellied Snakes.

Controlling for the effects of month, site, and time of capture, we captured significantly more Common Gartersnakes $(z=4.47, P<0.001)$ and Red-bellied Snakes $(z=9.196, P<0.001)$ in the field than in forest (Figure 1). In fact, only one Common Gartersnake and seven Red-bellied Snakes were captured in forest. We also captured more snakes in mid-season (June to July) than in early (May) and in late season (September to November): Common Gartersnake: $z=2.42, P=0.016$; Red-bellied Snake: $z=2.875, P=0.004$ (Figure 2). Whereas Common Gartersnakes did not seem to have a preference between tin and plywood coverboards $(z$ $=0.11, P=0.91$; Figure 1 ), we captured more Redbellied Snakes under tin than plywood coverboards $(z=5.78, P<0.001$; Figure 1).

Temperature did not vary significantly between plywood and tin coverboards $(t=0.16, P=0.87$; Figure $3)$. Temperature varied significantly between coverboards in forest and those in fields only during the warmer months (May, June, and July). During these months, temperatures under coverboards in fields were on average $8.8^{\circ} \mathrm{C}$ higher than under coverboards in forest ( $t=3.46, P<0.001$; Figure 3$)$. Coverboards in forests never warmed to the preferred temperature range of either Red-bellied Snakes (about $26.5^{\circ} \mathrm{C}$; Brattstrom 1965) or Common Gartersnakes $\left(24.5^{\circ}-30.7^{\circ} \mathrm{C}\right.$, Peterson et al. $1987 ; 25.5 \pm 0.4^{\circ} \mathrm{C}$ [SE] to $27.4 \pm$ $0.3^{\circ} \mathrm{C}$, Halliday and Blouin-Demers 2016; Figure 3). 

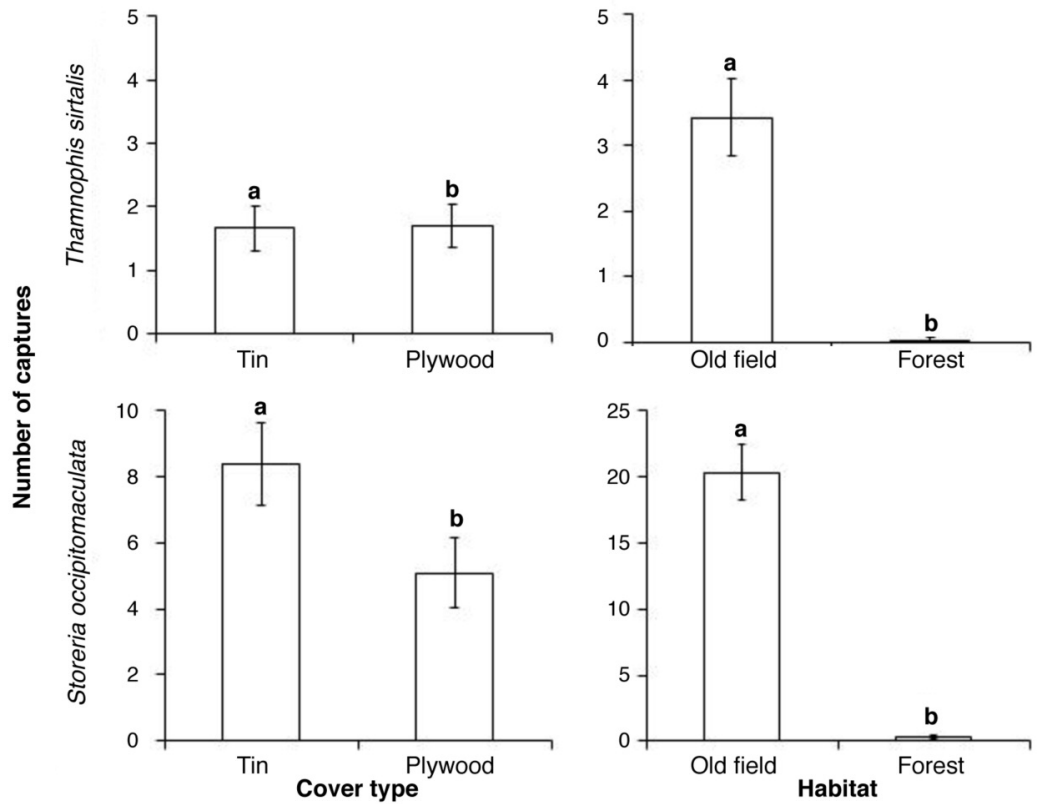

FIGURE 1. Number of captures of Red-bellied Snakes (Storeria occipitomaculata; $n=242$ ) and Common Gartersnakes (Thamnophis sirtalis; $n=90$ ) under plywood and tin coverboards in old field and forest in Gatineau Park, Quebec, Canada, 14 May to 16 November 2015. Each bar represents mean daily captures across four study sites. In each graph, means with the same letter are not significantly different, and error bars represent the standard error.

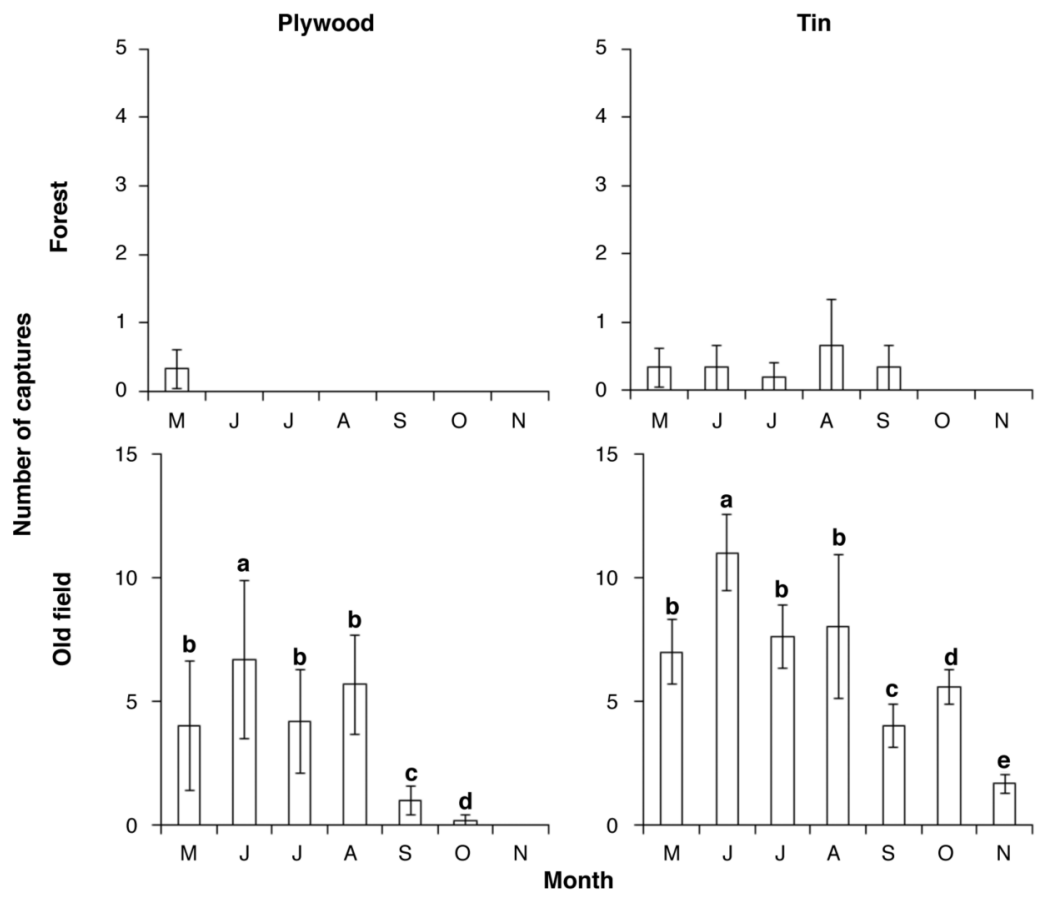

FIGURE 2. Number of captures by month of Red-bellied Snakes (Storeria occipitomaculata; $n=242$ ) under plywood and tin coverboards in old field and forest in Gatineau Park, Quebec, Canada, 14 May to 16 November 2015. Each bar represents mean monthly captures across all four study sites. In each graph, means with the same letter are not significantly different, and error bars represent the standard error. 

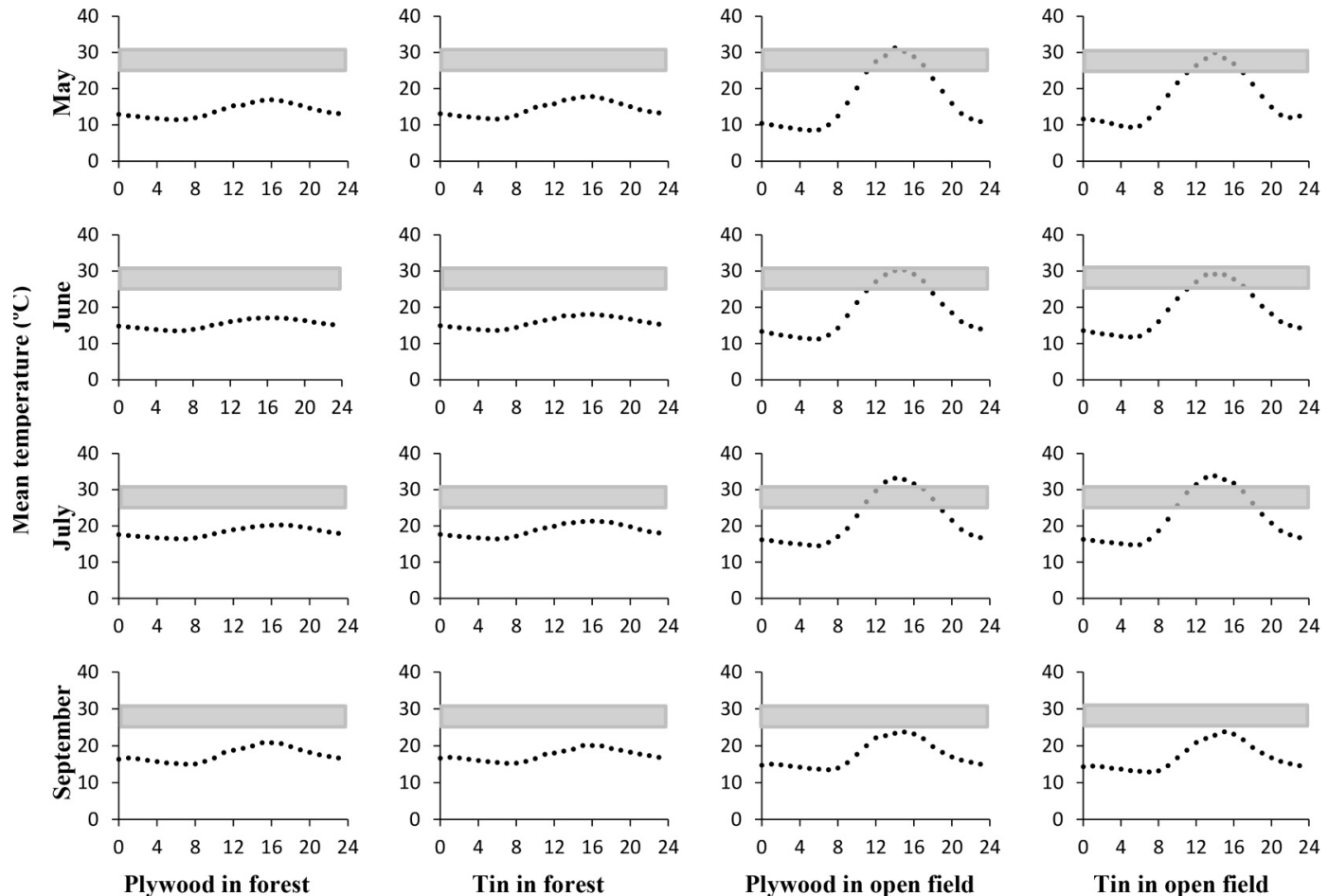

Time (h)

Plywood in open field

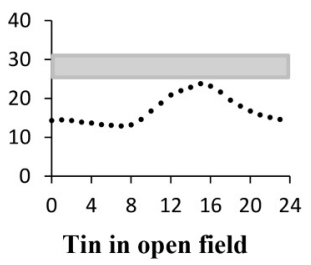

FiguRE 3. Mean temperature profiles under plywood and tin coverboards in old field and forest in Gatineau Park, Quebec, Canada, 2015. The grey rectangle represents the mean preferred temperature of Common Gartersnakes (Thamnophis sirtalis): $24.5-30.7^{\circ} \mathrm{C}$ (Peterson 1987).

\section{Discussion}

Both Common Gartersnakes and Red-bellied Snakes strongly preferred old field over forests, a pattern also observed in previous studies of other snakes (Charland and Gregory 1995; Row and Blouin-Demers 2006b; Kapfer et al. 2008; Lagory et al. 2009; Halliday and Blouin-Demers 2016). Old fields offered significantly higher temperatures than forests, particularly in May, June, and July. These patterns are consistent with the hypothesis that northern snakes are more abundant in open habitats because of their high thermal quality. Halliday and Blouin-Demers (2016) demonstrated that Common Gartersnakes prefer open habitats and that open habitats offer the best thermal conditions and the greatest fitness in terms of reproductive output and growth rate. Similarly, Black Ratsnakes use open habitats to increase fitness (measured by locomotor performance; Blouin-Demers and Weatherhead 2008). It is important to note that, although open habitats are preferred by many snake species, forest can still be important. For example, Eastern Massasauga Rattlesnakes (Sistrurus catenatus) prefer forest for hibernation (Harvey and Weatherhead 2006).
Most Common Gartersnakes and Red-bellied Snakes were captured from May to August with a peak in June and July, which corresponds with the highest maximum temperatures. Because body temperature directly affects physiological, reproductive, and ecological performance (Huey 1982), it is likely that the high number of captures during warmer months results from favourable thermal conditions. From May to August, high solar radiation heated the coverboards in old fields rendering them useful for behavioural thermoregulation.

It is worth noting that this study took place in a challenging thermal environment for ectotherms, where thermal quality is expected to be a strong predictor of habitat selection. In more southern and tropical locations, snakes often use forest (Luiselli and Capizzi 1997; Baxley et al. 2011; Steen et al. 2012), suggesting that thermal quality may not be a strong predictor of habitat selection in warmer areas. In Illinois, a less thermally challenging environment, Black Ratsnakes use forest more and forest edges less than populations of the same species in Ontario (Carfagno and Weatherhead 2006). Similarly, Five-lined Skink (Plestiodon fasciatus) uses open habitats in the northern part of its 
range (Quirt et al. 2006; Brazeau 2016), whereas it is found in forests in the southern part of its range (Watson and Gough 2012). Therefore, although northern populations of species, such as Common Gartersnake and Red-bellied Snake, prefer open habitats because of their thermal needs, southern populations of the same species may prefer different habitats for other reasons, such as prey density (Madsen and Shine 1996; Wasko and Sasa 2012).

Another possible explanation for the preference of northern snakes for open habitats is that coverboards act as refuges reducing predation risk associated with open habitats. Cover serves both as a resting place to avoid detection (Webb and Whiting 2005) and as a refuge for individuals that have been detected in open habitats (Martin and Lopez 2015). In fact, small snakes are found more frequently under cover in open habitats than large snakes, most likely because small snakes use cover as protection from predators (Gregory and Tuttle 2016).

Tin was preferred over plywood coverboards by Red-bellied Snakes, as also observed in some other snakes (Engelstoft and Ovaska 2000; Halliday and Blouin-Demers 2015). Although Engelstoft and Ovaska (2000) believed this was because tin is a better thermal conductor than plywood, we did not detect a significant difference between temperatures under tin and plywood coverboards. Furthermore, Common Gartersnakes did not prefer tin coverboards, but this may be a result of fewer captures ( 90 Common Gartersnakes versus 242 Red-bellied Snakes) and, thus, less power to detect a preference. The intriguing preference for tin over plywood coverboards in several snakes warrants further study.

In conclusion, Common Gartersnakes and Red-bellied Snakes were more abundant in old fields than in forest, confirming the preference of northern snakes for open habitats, likely because such habitats facilitate behavioural thermoregulation. However, an important caveat must be made: snakes were sampled exclusively with coverboards, and coverboards may be more attractive to snakes in open habitats than in closed habitats. For instance, we showed that coverboards in fields became warmer than coverboards in forest because they received more solar radiation. In fact, coverboards in forest never reached the preferred body temperature range of small northern snakes. Therefore, it is possible that coverboards in fields are more attractive to snakes because of their superior thermal attributes and, thus, are used more than coverboards in forest. If this is the case, the number of captures under coverboards may not be an accurate reflection of the relative density of snakes in the two habitats. This potential bias clearly deserves further study using different sampling methods.

\section{Acknowledgements}

We are grateful to William Halliday and James Paterson for their help with analyses. We are indebted to Caroline Gagné of the Nature Conservancy of Canada, to Isabelle Beaudoin-Roy, Catherine Verreault, and Jocelyne Jacob of the National Capital Commission, and to the Natural Sciences and Engineering Research Council of Canada for financial support. We thank Audrey Paquette and Mélanie Routh of the National Capital Commission for providing detailed descriptions of the study sites. We also thank Simon Pelletier, Pierre-André Bernier, and Sylvain Giguère for their help in setting up the coverboards.

\section{Literature Cited}

Baxley, D., G. Lipps, and C. Qualls. 2011. Multiscale habitat selection by black pine snakes (Pituophis melanoleucus lodingi) in southern Mississippi. Herpetologica 67: 154 166. https://doi.org/10.1655/HERPETOLOGICA-D-1000029.1

Blouin-Demers, G., and P. Weatherhead. 2001. An experimental test of the link between foraging, habitat selection and thermoregulation in black rat snakes Elaphe obsoleta obsoleta. Journal of Animal Ecology 70: 1006-1013. https: //doi.org/10.1046/j.0021-8790.2001.00554.x

Blouin-Demers, G., and P. Weatherhead. 2008. Habitat use is linked to components of fitness through the temperaturedependence of performance in ratsnakes (Elaphe obsoleta). Israel Journal of Ecology \& Evolution 54: 361-372. https://doi.org/10.1560/IJEE.54.3-4.361

Brattstrom, B. 1965. Body temperatures of reptiles. American Midland Naturalist 73: 376-422. https://doi.org/10.2307 $/ 2423461$

Brazeau, D. J. 2016. Habitat selection in the common fivelined skink near the northern extent of its range. M.Sc. thesis, Lakehead University, Thunder Bay, Ontario, Canada.

Brown, J. 1984. On the relationship between abundance and distribution of species. American Naturalist 124: 255-279. https://doi.org/10.1086/284267

Carfagno, G., and P. Weatherhead. 2006. Intraspecific and interspecific variation in use of forest-edge habitat by snakes. Canadian Journal of Zoology 84: 1440-1452. https: //doi.org/10.1139/z06-124

Charland, M., and P. Gregory. 1995. Movements and habitat use in gravid and nongravid female garter snakes (Colubridae: Thamnophis). Journal of Zoology 236: 543-561. https://doi.org/10.1111/j.1469-7998.1995.tb02731.x

Cooper, Jr., W. E., J. H. Van Wyk, and P. le F. N. Mouton. 1999. Incompletely protective refuges: selection and associated defences by a lizard, Cordylus cordylus (Squamata: Cordylidae). Ethology 105: 687-700. https://doi.org/10.10 46/j.1439-0310.1999.00447.x

Dobzhansky, T. 1950. Mendelian populations and their evolution. American Naturalist 84: 401-418.

Engelstoft, C., and K. E. Ovaska. 2000. Artificial coverobjects as a method for sampling snakes (Contia tenuis and Thamnophis spp.) in British Columbia. Northwestern Naturalist 81: 35-43. https://doi.org/10.2307/3536898

Goldsbrough, C. L., R. Shine, and D. F. Hochuli. 2006. Factors affecting retreat-site selection by coppertail skinks (Ctenotus taeniolatus) from sandstone outcrops in eastern 
Australia. Austral Ecology 31: 326-336. https://doi.org/10 $.1111 / \mathrm{j} .1442-9993.2006 .01561 . \mathrm{x}$

Grant, B. W., A. D. Tucker, J. E. Lovich, A. M. Mills, P. M. Dixon, and J. Whitfield Gibbons. 1992. The use of coverboards in estimating patterns of reptile and amphibian biodiversity. Pages 379-403 in Wildlife 2001: Populations. Edited by D. R. McCullough and R. H. Barrett. Elsevier Applied Science, London, United Kingdom. https://doi.org /10.1007/978-94-011-2868-1 31

Gregory, P. T., and K. N. Tuttle. 2016. Effects of body size and reproductive state on cover use of five species of temperate-zone natricine snakes. Herpetologica 72: 64-72. http://doi.org/10.1655/HERPETOLOGICA-D-15-00021

Halliday, W., and G. Blouin-Demers. 2015. Efficacy of coverboards for sampling small northern snakes. Herpetology Notes 8: 309-314.

Halliday, W. D., and G. Blouin-Demers. 2016. Differential fitness in field and forest explains density-independent habitat selection by gartersnakes. Oecologia 181: 841-851. https://doi.org/10.1007/s00442-016-3605-6

Harvey, D. S., and P. J. Weatherhead. 2006. Hibernation site selection by eastern massasauga rattlesnakes (Sistrurus catenatus catenatus) near their northern range limit. Journal of Herpetology 40: 66-73. https://doi.org/10.1670/89-05A.1

Hecnar, S. J., and D. R. Hecnar. 2011. Microhabitat selection of woody debris by Dekay's brownsnake (Storeria dekayi) in a dune habitat in Ontario, Canada. Journal of Herpetology 45: 478-483. https://doi.org/10.1670/10-219.1

Houze, Jr., C. M., and C. R. Chandler. 2002. Evaluation of coverboards for sampling terrestrial salamanders in South Georgia. Journal of Herpetology 36: 75-81. https://doi.org /10.1670/0022-1511(2002)036[0075:EOCFST]2.0.CO;2

Huey, R. 1982. Temperature, physiology, and the ecology of reptiles. Biology of the Reptilia 12: 25-91.

Huey, R. B., C. R. Peterson, S. J. Arnold, and W. P. Porter. 1989. Hot rocks and not-so-hot rocks: retreat-site selection by garter snakes and its thermal consequences. Ecology 70 : 931-944. https://doi.org/10.2307/1941360

Hyde, E. J., and T. R. Simons. 2001. Sampling plethodontid salamanders: sources of variability. Journal of Wildlife Management 65: 624-632. https://doi.org/10.2307/3803013

Kapfer, J. M., J. R. Coggins, and R. Hay. 2008. Spatial ecology and habitat selection of bullsnakes (Pituophis catenifer sayi) at the northern periphery of their geographic range. Copeia 2008: 815-826. https://doi.org/10.1643/CE-07-104

Krohmer, R. W. 1989. Body temperature relationships in the lined snake, Tropidoclonion lineatum. Comparative Biochemistry and Physiology Part A: Physiology 92: 541-543. https://doi.org/10.1016/0300-9629(89)90362-9

Lagory, K. E., L. J. Walston, C. Goulet, R. A. Van Lonkhuyzen, S. Najjar, and C. Andrews. 2009. An examination of scale-dependent resource use by eastern hognose snakes in southcentral New Hampshire. Journal of Wildlife Management 73: 1387-1393. https://doi.org/10.2193/2008-422

Luiselli, L., and D. Capizzi. 1997. Influences of area, isolation and habitat features on distribution of snakes in Mediterranean fragmented woodlands. Biodiversity \& Conservation 6: 1339-1351. https://doi.org/10.1023/A:101833351 2693

MacArthur, R. H. 1972. Geographical Ecology. Harper and Row. Princeton University Press, Princeton, New Jersey, USA.

Madsen, T., and R. Shine. 1996. Seasonal migration of predators and prey - a study of pythons and rats in tropical Australia. Ecology 77: 149-156. https://doi.org/10.2307/226 5663
Martin, J., and P. Lopez. 2015. Hiding time in a refuge. Pages 227-261 in Escaping from Predators: An Integrative View of Escape Decisions. Edited by W. E. Cooper, Jr. and D. T. Blumstein. Cambridge University Press, United Kingdom. https://doi.org/10.1017/CBO9781107447189

Martino, J. A., R. G. Poulin, D. L. Parker, and C. M. Somers. 2011. Habitat selection by grassland snakes at northern range limits: implications for conservation. Journal of Wildlife Management 76: 759-767. https://doi.org /10.1002/jwmg. 313

Peterson, C. R. 1987. Daily variation in the body temperatures of free-ranging garter snakes. Ecology 68: 160-169. https://doi.org/10.2307/1938816

Peterson, C. R., A. R. Gibson, and M. E. Dorcas. 1993. Snake thermal ecology: the causes and consequences of body temperature variation. Pages 241-314 in Snakes: Ecology and Behavior. Edited by R. A. Seigel and J. Collins. McGraw-Hill, Toronto, Ontario, Canada.

Quirt, K. C., G. Blouin-Demers, B. J. Howes, and S. C. Lougheed. 2006. Microhabitat selection of five-lined skinks in northern peripheral populations. Journal of Herpetology 40: 335-342. https://doi.org/10.1670/0022-1511 (2006)40[335:MSOFSI]2.0.CO;2

R Core Team. 2012. R: A language and environment for statistical computing. R Foundation for Statistical Computing, Vienna, Austria.

Reinert, H. K. 1993. Habitat selection in snakes. Pages 201240 in Snakes: Ecology and Behavior. Edited by R. A. Seigel and J. Collins. McGraw-Hill, Toronto, Ontario, Canada.

Reinert, H., and W. Kodrich. 1982. Movements and habitat utilization by the massasauga, Sistrurus catenatus catenatus. Journal of Herpetology 16: 162-171. https://doi.org $/ 10.2307 / 1563809$

Row, J. R., and G. Blouin-Demers. 2006a. Thermal quality influences habitat selection at multiple spatial scales in milksnakes. Ecoscience 13: 443-450. https://doi.org/10 .2980/1195-6860(2006)13[443:TQIHSA]2.0.CO;2

Row, J. R., and G. Blouin-Demers. 2006b. Thermal quality influences effectiveness of thermoregulation, habitat use, and behaviour in milk snakes. Oecologia 148: 1-11. https: //doi.org/10.1007/s00442-005-0350-7

Ryan, T. J., T. Philippi, Y. A. Leiden, M. E. Dorcas, T. B. Wigley, and J. W. Gibbons. 2002. Monitoring herpetofauna in a managed forest landscape: effects of habitat types and census techniques. Forest Ecology and Management 167: 83-90. https://doi.org/10.1016/S0378-1127(01)006922

Sagarin, R. D., S. D. Gaines, and B. Gaylord. 2006. Moving beyond assumptions to understand abundance distributions across the ranges of species. Trends in Ecology \& Evolution 21: 524-530. https://doi.org/10.1016/j.tree.2006.06.008

Steen, D. A., C. J. McClure, J. C. Brock, D. C. Rudolph, J. B. Pierce, J. R. Lee, W. J. Humphries, B. B. Gregory, W. B. Sutton, L. L. Smith, and D. L. Baxley. 2012. Landscape-level influences of terrestrial snake occupancy within the southeastern United States. Ecological Applications 22:1084-97. https://doi.org/10.1890/11-1777.1

Wasko, D. K., and M. Sasa. 2012. Food resources influence spatial ecology, habitat selection, and foraging behavior in an ambush-hunting snake (Viperidae: Bothrops asper): an experimental study. Zoology 115: 179-187. https://doi.org /10.1016/j.zool.2011.10.001

Watson, C. M., and L. Gough. 2012. The role of temperature in determining the distribution and coexistence of three 
species of Plestiodon. Journal of Thermal Biology 37: 374 379. http://doi.org/10.1016/j.jtherbio.2012.02.001

Webb, J. K., and M. J. Whiting. 2005. Why don't small snakes bask? Juvenile broad-headed snakes trade thermal benefits for safety. Oikos 110: 515-522. http://doi.org/10 $.1111 / \mathrm{j} .0030-1299.2005 .13722 . \mathrm{x}$
Winne, C. T., J. D. Willson, K. M. Andrews, and R. N. Reed. 2006. Efficacy of marking snakes with disposable medical cautery units. Herpetological Review 37: 52-54.

Received 9 July 2016

Accepted 30 May 2017

\section{SUPPlementary Material:}

APPENDIX S1: Detailed descriptions of the study sites, provided by Audrey Paquette and Mélanie Routh under the supervision of Jocelyne Jacob, National Capital Commission, Gatineau Park. 